\title{
Design Optimization and Fatigue Analysis for Seal Joint of Control Rod Drive Mechanism
}

Shao Xuejiao "Dujuan

Nuclear Power Institute of China ,Chengdu,610213,China

\begin{abstract}
Two kinds of seal joint thickness of control rod drive mechanism seal house were analyzed on stress and fatigue by using finite element method, and it provides analytical basis for equipment optimization, design manufacturing and problem handing. In the fatigue computing, all the transients were grouped into several groups, so as to separate the transients not at the same stage obviously. Meanwhile, the transients can be respectively combined in every group to reduce the redundant conservatism of computation. The elastoplastic strain correction factor was modified by analyzing thermal and mechanical load separately referring the rules of RCC-M 2002.By comparing the stress of two thickness joints, the results are found that the fatigue results of the thinner thickness are safer, but this is contrary to the rule of other results. The fatigue usage factor can be reduced by using modified elastoplastic strain correction factor when the amplify of the primary and secondary stress is large produced by both thermal load and mechanical load.
\end{abstract}

\section{INTRODUCTION}

The margin of safety will decrease if the aging of react pressure vessel is not be controlled, this will increase the risk of health and safety in public. The effects of LWR coolant environments on fatigue life in pressure vessel cannot be ignore.

The LWR coolant environments contain the temperature; dissolved-oxygen (DO) level in water; strain rate; strain amplitude which are the key parameters that influence fatigue life. In the stage of designing engineering, the conservatism which was considered by fatigue strain data is not enough.

Two approaches have been proposed for incorporating the environmental effects : (a) develop new fatigue design curves for LWR applications (b) use an environment correction factor to account for the effects of the coolant environment,

The second approach, proposed by M.Higuchi and K.Iida ${ }^{[1,2]}$, considers the effects of reactor coolant environments on fatigue life in terms of an environmental correction factor Fen, which is the ratio of fatigue life in air at room temperature to that in water under reactor operating conditions. Specific expressions for Fen, based on statistical models and on the correlations developed by the Environmental Fatigue Data Committee of the Thermal and Nuclear Power Engineering Society of Japan, have been proposed.

The fatigue of key parts on control rod drive mechanisms was analyzed considering the influence of environmental fatigue cased by the coolant in the react pressure vessel. The elastoplastic strain correction factor was modified by analyzing thermal and mechanical loads separately referring the rules of RCC-M $2002^{[3]}$.

\section{MODEL AND CALCULATION APPROACH}

\subsection{Finite element model}

The axi-symmetric model was created for the analysis which comprises the rop section of the adapter, the lower section of the latch housing seal house, the assembly threading and the thin-lip seal. A detailed view of the mesh density including the cut locations is shown in Fig. 1.The mechanical loads considered in this calculation are structural temperatures, internal pressure transient, operating basis earthquake(OBE). Only a vertical constraint is necessary to restrain the bottom of the model.

In the fatigue calculation, the transient thermal and pressures boundary condition were applied to the finite element model, the node stress caused by temperature grads and pressure will combine with the earthquake loads, the time of the peak value was determined as the event of fatigue analysis. If the primary plus secondary stress range $S_{n}$ exceeds the $3 S_{m}$ limit, the peak value was modified by the elastoplastic strain correction factor. Based on the fatigue design curves for structural and the number of transients, the usage factor can be calculated by the software of ANSYS.

\footnotetext{
Shao Xuejiao: shaoxuejiao@163.com
} 


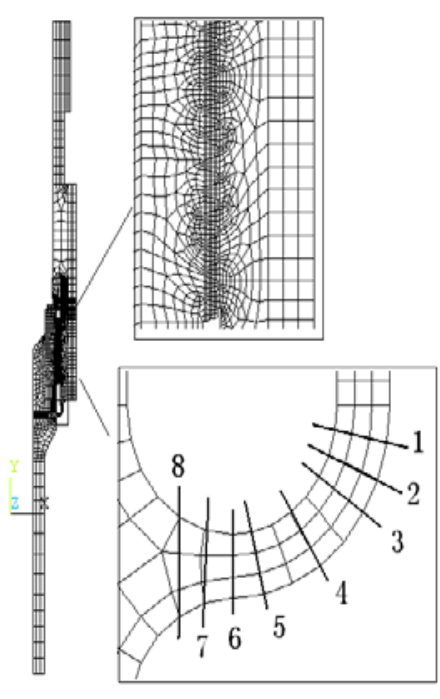

Figure 1 The finite element model and stress cut location

\subsection{Fatigue analysis approach and Ke modifiy}

In the ANSYS, the elastoplastic strain correction factor $\left(\mathrm{K}_{\mathrm{e}}\right)$ is determined from the $\mathrm{S}_{\mathrm{n}}$ value as follows:

$\mathrm{S}_{\mathrm{n}} \leqslant 3 \mathrm{~S}_{\mathrm{m}}, \quad \mathrm{K}_{\mathrm{e}}=1$

$3 \mathrm{~S}_{\mathrm{m}} \leqslant \mathrm{S}_{\mathrm{n}} \leqslant 3 \mathrm{~S}_{\mathrm{m}}, \quad \mathrm{K}_{\mathrm{e}}=1+(1-\mathrm{n})\left(\mathrm{S}_{\mathrm{n}} / \mathrm{S}_{\mathrm{m}}-1\right) / \mathrm{n}(\mathrm{m}-1)$

$\mathrm{S}_{\mathrm{n}} \geqslant 3 \mathrm{~S}_{\mathrm{m}}, \quad \mathrm{K}_{\mathrm{e}}=1 / \mathrm{n}$

The values for $m$ and $n$ are 1.7 and 3 for austenitic stainless steel. The $K_{e}$ factor is determined from the $S_{n}$ range and the total stress range $S_{p}$, yielding to the Salt stress range used for fatigue analyses:

$\mathrm{S}_{\mathrm{alt}}=\mathrm{K}_{\mathrm{e}} \mathrm{S}_{\mathrm{p}} / 2$

According to the edition of RCCM 2002, The value of $\mathrm{S}_{\text {alt }}$ takes the following value ${ }^{[4-6]}$ :

$\mathrm{S}_{\mathrm{alt}}=\left(\mathrm{K}_{\mathrm{emech}} \mathrm{S}_{\text {pmech }}+\mathrm{K}_{\text {etherm }} \mathrm{S}_{\text {ptherm }}\right) / 2$

Where $S_{\mathrm{p}(\text { mech) }}$ is the range of the mechanical part of the stresses, $S_{\mathrm{p} \text { (therm) }}$ is the range of the thermal part of the stresses. Elastoplastic stress correction factor for the thermal part, calculated in the case of austenitic stainless steels, by the following formula:

$\mathrm{K}_{\text {etherm }}=\max \left\{1.86\left[1-1 /\left(1.66+\mathrm{S}_{\mathrm{n}} / \mathrm{S}_{\mathrm{m}}\right)\right], 1\right\}$

To sum up, the computing method of ANSYS is over conservation, the new fatigue results were get using the expression (3) by user programming.

\subsection{Environmental fatigue analysis}

The first approach, the temporary fatigue design curve for LWR application supplied by NUREG/CR$5999(1993)^{[7]}$ is shown in Fig.2 used to analyze the key parts on control rod drive mechanisms.

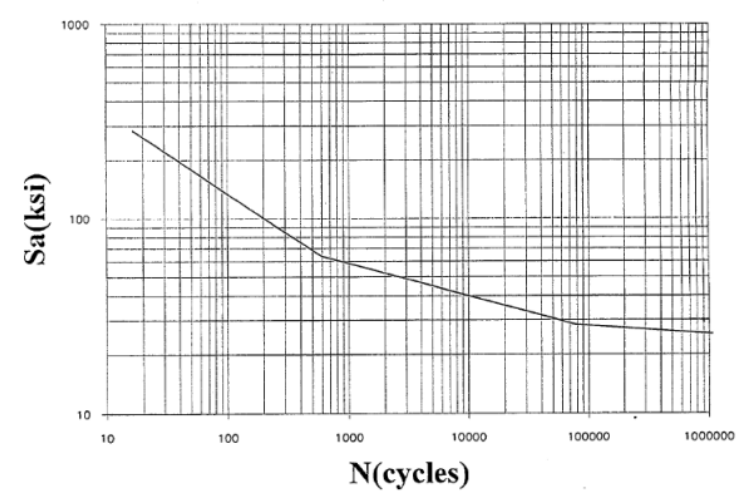

Figure 2 The temporary fatigue data for austenitic stainless steel

The second approach, proposed by Higuchi and Iida, considers the effects of reactor coolant environments on fatigue life in terms of an environmental correction factor Fen, which is the ratio of fatigue life in air at room temperature to that in water under reactor operating conditions. The Fen of austenitic stainless steels is represented by

Fen $=\exp \left(0.935-\mathrm{T}^{\prime} \varepsilon \mathrm{O}^{\prime}\right)$

where $\mathrm{T}^{\prime}, \mathrm{O}^{\prime}$, and $\dot{\boldsymbol{\varepsilon}}^{\prime}$ are transformed temperature, DO, and strain rate, respectively, defined as follows:

$$
\begin{aligned}
& \mathrm{T}^{\prime}=0 \quad\left(\mathrm{~T}<150^{\circ} \mathrm{C}\right) \\
& \mathrm{T}^{\prime}=(\mathrm{T}-150) / 175 \quad\left(150 \leq \mathrm{T}<325^{\circ} \mathrm{C}\right) \\
& \mathrm{T}^{\prime}=1 \quad\left(\mathrm{~T} \geq 325^{\circ} \mathrm{C}\right)
\end{aligned}
$$

$$
\begin{array}{r}
\varepsilon^{\prime}=0 \quad(\dot{\boldsymbol{\varepsilon}}>0.4 \% / \mathrm{s}) \\
\varepsilon^{\prime}=\ln (\dot{\boldsymbol{\varepsilon}} / 0.4) \quad(0.0004 \leq \dot{\boldsymbol{\varepsilon}} \leq 0.4 \% / \mathrm{s}) \\
\varepsilon^{\prime}=\ln (0.0004 / 0.4) \quad(\dot{\boldsymbol{\varepsilon}}< \\
0.0004 \% / \mathrm{s})
\end{array}
$$

$\mathrm{O}^{\prime}=0.26$

The critical parameters that influence fatigue life are summarized :(1)Strain Rate: fatigue life decreases with decreasing strain rate.(2)Dissolved Oxygen in Water: the fatigue lives of austenitic are decreased significantly in low-DO water. The decrease in life is greater at low strain rates and high temperatures.(3) Temperature: the data suggest a lower threshold temperature of $150^{\circ} \mathrm{C}$.

\section{SIMULATIONS AND DISCUSSIONS}




\subsection{Effect of Ke}

The fatigue results of the cut locations were listed In Table 1 which show the results exceed 1 only using the ANSYS, the result can reduce if adopt the user programming according the rules of RCCM 2002. The results show that the precision of fatigue usage factor can be elevated by using modified $\mathrm{K}_{\mathrm{e}}$ when the amplify of the primary and secondary stress is large to some extent.

Table 1. The effect of $\mathrm{Ke}$ on fatigue usage

\begin{tabular}{c|c|c|c|c}
\hline \multirow{2}{*}{ Section } & \multicolumn{2}{|c|}{$u\left(K_{\mathrm{e}}\right)$} & \multicolumn{2}{c}{$u\left(\operatorname{modified} K_{\mathrm{e}}\right)$} \\
\cline { 2 - 5 } & in & out & in & out \\
\hline 1 & 1.152 & 0.000 & 0.357 & 0.001 \\
\hline 2 & 1.805 & 0.003 & 0.646 & 0.008 \\
\hline 3 & 1.481 & 0.001 & 0.663 & 0.003 \\
\hline 4 & 0.012 & 0.000 & 0.022 & 0.000 \\
\hline 5 & 0.000 & 0.008 & 0.000 & 0.011 \\
\hline 6 & 0.482 & 2.236 & 0.292 & 0.513 \\
\hline 7 & 1.127 & 2.059 & 0.330 & 0.496 \\
\hline 8 & 0.041 & 0.109 & 0.041 & 0.077 \\
\hline
\end{tabular}

\subsection{Effect of environmental fatigue}

In the section, two approaches were adopted in evaluating the third section with one transient. The usage factor is 0.144 using the design fatigue curve, but the usage factor is 0.6173 if using the temporary fatigue curve considering the effects of the coolant environment. This approach need compute the every key part of equipment once again, the computing cost is high to some extent.

For the second approach, the second, the forth and the fifth column of the table 2 show the strain rate influence the Fen obviously when in the high temperature. If the temperature is higher than $150^{\circ} \mathrm{C}$, the effect of temperature on Fen is sensitive. This approach can make use of existing result effectively.

Table 2. The effect of Fen on fatigue usage

\begin{tabular}{c|c|c|c|c|c}
\hline$/$ & 1 & 2 & 3 & 4 & 5 \\
\hline $\begin{array}{c}\text { temperature/ } \\
{ }^{\circ} \mathrm{C}\end{array}$ & 154.7 & 154.7 & 20 & 290.8 & 290.8 \\
\hline $\begin{array}{c}\text { Strain rate/s- } \\
1\end{array}$ & $\begin{array}{c}5.98 \times 1 \\
0^{-6}\end{array}$ & $\begin{array}{c}2.0 \times 10^{-} \\
6\end{array}$ & $\begin{array}{c}5.98 \times 1 \\
0^{-6}\end{array}$ & $\begin{array}{c}2.0 \times 10 \\
-6\end{array}$ & $\begin{array}{c}4.0 \times 10 \\
-3\end{array}$ \\
\hline $\mathrm{T}^{\prime}$ & 0.027 & 0.027 & 0 & 0.805 & 0.805 \\
\hline $\mathrm{O}^{\prime}$ & 0.26 & 0.26 & 0.26 & 0.26 & 0.26 \\
\hline$\varepsilon^{\prime}$ & -6.506 & -6.908 & -6.506 & -6.908 & 0 \\
\hline Fen & 2.66 & 2.67 & 2.55 & 10.81 & 2.55 \\
\hline Initial usage & 0.144 & 0.144 & 0.144 & 0.144 & 0.144 \\
\hline $\begin{array}{c}\text { Modified } \\
\text { usage }\end{array}$ & 0.383 & 0.384 & 0.367 & 1.56 & 0.367 \\
\hline
\end{tabular}

(1) The precision of fatigue usage factor can be elevated by using modified $\mathrm{K}_{\mathrm{e}}$ when the amplify of the primary and secondary stress is large to some extent.

(2) The difference of results for the austenitic stainless steels is obvious if considering the coolant environmental fatigue comparing with the results in air.

References

1. M.Higuchi and K.Iida, "Fatigue Strength Correction Factors for Carbon and Low-Alloy Steels in Oxygen-Containing High-Temperature Water", Nucl. Eng. Des. 129, 293-306(1991).

2. K.Iida, T.Bannai, M.Higuchi, K.Tsusumi, and K.Sakaguchi, "Comparison of Japanese MITI Guideline and Other Methods for Evaluation of Environmental Fatigue Life Reduction", in Pressure Vessel and Piping Codes and Standards, PVP Vol.419, M.D. Rana,ed., American Society of Mechanical Engineers, New York,pp.73-82(2001).

3. Afcen. RCC-M: Editon 2000 and Addendum June 2002, Section:Subsection B , 2002.

4. Prost J P, Arnaudeau F. Elastic plastic strain correction factor in stainless steel pipes and Nozzles Subjected to Thermal Shocks . 4th ICPVT ,1980: 80-90.

5. Grandemange J M., Héliot J., Vagner J. Improvements on Fatigue Analysis Methods for the Design of Nuclear Components Subjected to the French RCC-M Code.WRC Bulletin , 1991(2):361.

6. FAMATOME ANP, APPENDIX A -Pastic strain correction factors.

7. S.Majumdar, O.K.Chopra, and W.J.Shack, “ Interim Fatigue Design Curves for Carbon, Low-Alloy, and Austenitic Stainless Steels in LWR Environments", NUREG/CR-5999,1993.

\section{CONCLUSIONS}

